\title{
EDUCAÇÃO CORPORAL NA CULTURA MODERNISTA - LIBERDADE E MERCANTILIZAÇÃO ${ }^{1}$
}

\author{
Kent Sjöström \\ Professor associado na Malmö Theatre Academy, Lund University (Suécia). Ator e encenador \\ kent.sjostrom@thm.lu.se \\ Tradução: Carina Corá e Cláudia Müller
}

Resumo

A prática do ator e o treinamento corporal durante o século $X X$ estão especificamente relacionados não só com diferentes técnicas corporais, mas também com linguagem, sociedade moderna e o conceito de liberdade. $\mathrm{O}$ nacionalismo, o anti-intelectualismo, o purismo corporal e vitalista e a distância cética do projeto moderno no início do século XX servem de ponto de partida para uma discussão sobre o corpo do ator e o treinamento corporal. De um ponto de vista crítico, fenômenos como o orientalismo, o escapismo rural e a quantidade de técnicas corporais na formação dos atores na segunda metade do século XX são justapostos com retórica sobre a liberdade corporal e um consumismo de acordo com tendências no resto da vida da sociedade. O discurso em torno do conceito de liberdade corporal pode ser visto como um projeto disciplinar e uma mercantilização do corpo no mercado atual. Uma discussão contemporânea sobre identidades - como construções, autenticidade e pós-colonialismo - pode influenciar a educação dos atores e torná-la mais individualizada, mas também aumentar a consciência dos valores e relações de poder que estão em jogo quando se trabalha com diferentes técnicas corporais nessa educação.

\section{Palavras-chave}

Treinamento de Atores. Técnicas Corporais. Discursos Corporais. Orientalismo. Vanguarda. Modernismo.
Abstract

The actor's practice and bodily training during the twentieth century are specifically related not only to different bodily techniques, but also to language, modern society, and the concept of freedom. Nationalism, anti-intellectualism, bodily and vitalistic purism, and a sceptical distance from the modern project at the beginning of the twentieth century serve as a starting point for a discussion about the actor's body and bodily training. From a critical point of view, phenomena like orientalism, rural escapism, and the amount of bodily techniques in actors' training in the second half of the twentieth century are juxtaposed with rhetoric about bodily freedom and a consumerism in line with tendencies in the rest of society. The discourse surrounding the concept of bodily freedom can be seen as a disciplinary project and a commodification of the body in the present-day marketplace. A contemporary discussion about identities - such as constructions, authenticity, and post-colonialism - might influence actors' education and make it more individualised, but also increase awareness of values and power relations that are at stake when working with different bodily techniques in such education.

Keywords

Actors' Training. Bodily Techniques. Bodily Discourses. Orientalism. Avant-Garde. Modernism .

1 Artigo publicado por Routledge online em 26 Mar 2015, aprovado para publicação com compra dos direitos pelo autor. O original: Kent Sjöström (2015) Bodily education in modernist culture - freedom and commodification, Theatre, Dance and Performance Training, 6:1, 72-84, DOI: 10.1080/19443927.2014.985895. http://dx.doi.org/10.1080/19443927.2014.985895. 
Meu objetivo neste artigo é discutir e analisar algumas tendências na educação corporal dos atores durante o século XX, especialmente aquelas que têm sua origem no movimento vanguardista. A seguir, tentarei identificar diferentes temas, como o ceticismo em relação à linguagem verbal, o orientalismo e o retiro rural, e a multiplicidade de técnicas corporais temas que contribuem para a compreensão da tensão entre os ideais de liberdade corporal, disciplina e mercantilização, e conectá-las ao que considero um discurso central no treinamento dos atores durante o século XX: a busca pela liberdade corporal.

\section{Zeitgeist: início do século XX}

No desenvolvimento do teatro europeu durante o século $X X$, é revelado um projeto físico - para o ator, um projeto de expressão ou libertação física, mais claramente refletido no movimento de vanguarda no início do século, mas também possível de se acompanhar no desenvolvimento de diferentes modelos pedagógicos de formação de atores ao longo deste período. Em interação com a sociedade circundante, cria-se um discurso corporal, fundado numa discussão do papel do corpo no trabalho criador do ator, especialmente em relação ao texto dramático escrito. Este movimento não nasceu num vácuo ideológico, mas foi inspirado pela nova cultura da fisicalidade que surgiu no início do século $X X$. O pesquisador teatral Mark Evans (2009, p. 23-31) remonta ainda mais, a meados do século XIX, e conecta tentativas para oferecer uma descrição sistemática da expressão corporal com a industrialização da época.

O estudioso de literatura Harold B. Segel
(1998), entre outros, mapeou e discutiu este zeitgeist em seu livro "Body Ascendant". No que se segue vou tentar dar um breve panorama das tendências que Segel considera refletir ou enquadrar o discurso corporal descrito acima. Segel cataloga as ideologias do pensamento que sustentam e explicam a cultura física emergente na virada do século e nas décadas seguintes. Não é inteiramente fácil encontrar um único termo que possa abranger as tendências divergentes que se desenvolvem com a filosofia, os movimentos políticos e a arte durante esses anos do modernismo inicial. Não se trata de um determinado programa ou de uma atitude política pronunciada, mas sim de uma tendência teórica que sustenta o corpo como fonte de conhecimento, mantendo uma atitude crítica em relação à linguagem e, mais especificamente, ao lado semântico da linguagem:

Uma cultura da mente pressupunha a primazia da palavra, mas a transvalorização modernista dos valores, tomando emprestado o termo de Nietzsche, questionou seriamente a autoridade epistemológica da linguagem. Os pensadores de então martelaram no pedestal em que a língua tinha estado majestosa por muito tempo. Eles pensavam que o corpo também era linguagem e, portanto, semanticamente digno. (Segel 1998, p. 1)

A paixão pelo físico e pelo intuitivo foi encontrada em filósofos como Friedrich Nietzsche e Henri Bergson, enquanto Sigmund Freud forneceu à psicologia uma construção teórica desafiadora na qual o inconsciente toma uma posição importante.

A primeira Olimpíada em 1896, o movimento de escotismo inglês (fundado em 1907) ou o movimento contemporâneo alemão Wandervögel podem ser vistos como respostas a 
perdas ou deficiências nacionais em conflitos armados:

Em quase todos os casos, a experiência da guerra - ou melhor, a derrota na guerra: os alemães na época de Napoleão, os franceses após a desastrosa guerra franco-prussiana de 1871, os britânicos após a guerra dos bôeres elevaram o nível de consciências sobre a necessidade de padrões físicos aprimorados (Segel, 1998, p. 209) ${ }^{1}$

As derrotas nacionais deram origem ao irredentismo, mais evidente na Alemanha durante a década de 1920, como resultado da Primeira Guerra Mundial e do Tratado de Versalhes. Segundo Segel, o nacionalismo e a criação da identidade nacional são movimentos políticos apoiados pela educação física e cultivados através do endurecimento físico e da pureza. Esta ideologia física do corpo forte e superior também contém as sementes do pensamento biológico racista: em Minha Luta², Adolf Hitler proclamou a importância da educação física dentro de seu programa político. (Segel 1998, p. 224)

O rápido ritmo de urbanização também foi visto pelo nazismo como uma ameaça a uma população vigorosa. As cidades atraíam pessoas de ambientes diversos, e para elementos conservadores essa era uma fonte de prostituição e decadência. A cidade e a mistura de pessoas foram consideradas ameaçadoras para o patrimônio völkisch, que era previsto para construir uma nova nação, e o anti-urbanismo se tornou uma parte importante da cultura popular; foi na luta com a natureza, e ao mesmo tempo na harmonia com ela, que a imagem do corpo saudável foi cultivada.
Essas idéias contêm uma exigência de excelência física, motivada por um grupo ou sociedade como um todo enfrentando desafios extraordinários do tipo como os encontrados em crise ou guerra. A resposta a estes desafios é um cidadão com certas competências físicas. Essas competências podem ser refletidas na pureza, no celibato, no ascetismo, na força da vontade, na força muscular, na intuição, na disciplina e na capacidade de ação. Também é claro quais traços são considerados opostos a estes: intelectualismo, reflexão, ambivalência e fraqueza física.

Em 1903, o autor alemão Frank Wedekind publicou uma novela bastante obscura: Mine-Haha, ou Sobre a Educação Corporal das Meninas. ${ }^{3}$ (Wedekind, 2010) O enredo da novela é baseado em um diário que o autor alega ter recebido de uma mulher idosa. Nesse diário, a mulher conta como, em sua infância, ela é colocada em um internato ao lado de outras meninas e como ela é criada e educada por meninas mais velhas para se tornar uma espécie de bailarina e intérprete de pantomima. O internato é isolado e cercado num grande parque, e é composto por vários edifícios: alguns para treinamento físico, outros para habitação. As meninas chegam ao internato quando têm poucos anos de idade, e são criadas e cuidadas pelas meninas ligeiramente mais velhas, que por sua vez são educadas pelas pré-adolescentes. Isso continua até que elas sejam consideradas aptas para executarem em público.

Cada parte de sua educação está focada na habilidade corporal, enquanto a leitura e outras formas de educação do intelecto estão ausentes. Fisicamente conduzidos pelas me-

3 No original, Mine-Haha, ou Über die körperliche Erziehung der jungen Mädchen. 
ninas de diferentes idades, os ideais incluem o desenvolvimento do movimento gracioso, o aprendizado de danças e a conquista da excelência ginástica, além do domínio do ritmo e da música. Mesmo o uso mais básico e comum do corpo é refinado: a perfeição ao andar ou mover as mãos cria a perfeição estética desejada. Elas são ensinadas como, nas palavras do narrador, "pensar com os nossos quadris". (Wedekind 2010, p. 9) Trata-se de uma educação física artística que conduz a um desempenho competente, mas combinado com uma completa negação de todo pensamento, leitura e reflexão. A narradora descreve como ela recorda suas amigas como nada além de criaturas físicas, nunca pelo que elas disseram ou expressaram: "Minha memória não preserva nenhuma impressão de como as meninas falavam. Só consigo me lembrar de como cada uma delas andava". (Wedekind 2010, p. 34) Nenhuma das meninas tinha seu próprio mundo mental ou singularidade, o que fazia todas as conversas maçantes.

Vejo a novela de Wedekind como uma sátira ou uma distopia de um zeitgeist no qual o intelectualismo foi colocado em oposição à vitalidade e à fisicalidade. Como uma distopia do desempenho fisicamente excelente sem a capacidade de pensamento ou de reflexão, a novela de Wedekind é instrutiva numa discussão sobre a fisicalidade e o anti-intelectualismo, tanto na sociedade como nas artes da performance.

Segel (1998, p. 221) descreve como o interesse pelo corpo como fonte de conhecimento e a fisicalidade como expressão da identidade intuitiva ou nacional interagiram com o anti-intelectualismo, que em certos países foi considerado mais fortemente amarrado ao desgosto pelo feminino e pelo judeu. A cultura judaica era considerada racional e intelectual, enquanto a feminilidade era associada à fraqueza e ao prazer. Paralelamente, havia entre muitos artistas um interesse no Oriente e Extremo Oriente, especialmente religiões como o hinduísmo e o budismo. Estes eram - por causa da ignorância - percebidos como sendo menos intelectuais do que o cristianismo, e especialmente como tendo mais aprovações das expressões físicas da espiritualidade.

\section{Artes do espetáculo}

Nas artes do espetáculo, especialmente aquelas caracterizadas pela expressão corporal, a cultura física descrita por Segel pode ser ligada em parte a nomes como Isadora Duncan, Émile Jacques-Dalcroze e a bailarina americana Ruth St. Denis, ou teóricos como o alemão George Fuchs, e por palavras como movimento rítmico e plasticidade. Significativo para o tempo é que St. Denis desenvolveu um repertório baseado na dança indiana e o que ela considerava a tradição do movimento egípcio, e em sua dança ela usou "um discurso falado de pseudo-hindi". (Segel 1998, p. 84)

As técnicas físicas foram tipicamente inspiradas pelo Oriente, como discutirei mais adiante. A dança e o teatro japoneses influenciaram o teatro europeu já na virada do século, e o ioga influenciou a visão de Constantin Stanislavsky, entre outros, da conexão mente-corpo. Uma outra característica dominante é descrita pelo pesquisador de teatro Christopher Innes (1993, p. 9-11, 82): o interesse pela mitologia, pela antropologia social e pelo subconsciente leva o teatro de vanguarda a um interesse pelo que Innes denomina 'primitivo'. De maneira semelhante e típica do seu tempo, o psicólogo 
Carl Gustav Jung combina esoterismo e psicologia com o orientalismo e a antropologia.

Como Segel, considero que a linha de pensamento acima é claramente visível no crescimento do modernismo teatral: o ceticismo em relação à linguagem como meio de comunicação pode ser encontrado no simbolismo, no culto da ação entre os futuristas italianos e nas experiências linguísticas dos dadaístas, mas também na criação da mímica moderna. Durante o final do século XIX, a mímica como forma de arte se torna mais sublime, um desenvolvimento que culminou na criação da mímica corporal de Étienne Decroux na década de 1930. Essa tendência para o sublime é articulada por Jean-Louis Barrault:

A mímica moderna tem um anseio pelo puro, e nega a si mesma a linguagem do mudo. Quer encarnar ação e nada além de ação e, se alguma coisa for acrescentada, será uma espécie de canto lírico de gestos, brotando de uma alma transbordante. O que há de novo na mímica moderna é que ela pode chegar até a tragédia. Torna-se uma arte nobre e, nessa medida, pode ser verdadeiramente comparada com a mímica oriental. (1979, p. 109-10)

Um olhar mais específico sobre o movimento de vanguarda dos anos 40 e mais tarde também revela uma forte influência da psicologia fisicamente orientada, com suas raízes nos pensamentos do psicanalista Wilhelm Reich sobre a libertação de um corpo inibido. Reich (Roach 1993, p. 219) descreve um corpo onde os músculos se transformaram até mesmo numa 'armadura', baseado numa visão do ser humano moderno como perturbado em sua conexão entre corpo e mente. Essas ideias influentes sobre um corpo livre foram formuladas anteriormente, mas nessa psicologia bioenergética também recebem uma base de fundamentação teórica.

Nos países nórdicos, o projeto físico teve sua descoberta artística durante os anos $60 \mathrm{e}$ mais tarde, com exercícios e ideias tomadas de Jerzy Grotowski, Vsevelod Meyerhold, Living Theatre, Rudolf von Laban e Antonin Artaud. Devido a essas influências, a educação física dos atores foi ampliada durante este período, desde principalmente esgrima, balé e, possivelmente, mímica, até uma pluralidade de técnicas, às quais voltarei em breve. Como eu elaborei mais cedo, a expressão física tem uma posição especial nas performances de palco do século XX.

Corpo e texto

Quando algo seria condenado como convencional ou retrocedente pelo movimento de vanguarda no teatro do século $X X$, ele era frequentemente associado a uma forte dependência do texto e da linguagem falada, ou recital, e com corpos se movendo de forma limitada ou cotidiana; de forma simplificada, o que é considerado "realismo" ou "naturalismo". De modo correspondente, o teatro vanguardista também foi caracterizado como espiritual, ritual e pela vontade de fazer sacrifícios, uma fisicalidade mais desafiadora e o questionamento do papel central do texto. (Innes, 1993, p. 3-4) O pesquisador de teatro Joseph R. Roach exemplifica essa tendência com o grupo de teatro americano Living Theatre:

Eles ensinaram resistência física contra as convenções de rigidez do teatro mecânico-literário em todas as suas manifestações repressivas - complexidade da tecnologia de produção, por exemplo, e scripts. O paradigma de Diderot, do Paradoxo à trilogia de Stanislavski, supõe a existência de um 
texto que, por sua natureza, impõese sobre a espontaneidade do ator... O movimento de vanguarda, do qual o Living Theatre fazia parte, em geral exaltava o impulso corporal do ator, o acontecimento, o automatismo polido, a seleção. (1993, p. 222)

Este desenvolvimento também estava distante do realismo, em direção a um teatro que destrói nossa visão cotidiana da realidade e reivindica a busca de algo mais profundo, mais essencial na existência humana, ou com o objetivo de retratar uma realidade incapaz de ser descrita por palavras, análise ou intelecto. Neste contexto, a tentativa de Antonin Artaud de alcançar uma linguagem corporal além do logos pode ser o exemplo mais radical de uma tendência que influenciou o teatro do século XX. Em 1932, Artaud escreve sobre sua relação com a palavra falada no palco:

Diálogo - algo escrito e falado - não pertence especificamente ao palco, mas aos livros. ... Eu sustento que está linguagem física, dirigida aos sentidos e independente da fala, deve primeiro satisfazer os sentidos. Deve haver poesia para os sentidos, assim como há para a fala, mas essa linguagem física e tangível a que me refiro é apenas teatral, na medida em que os pensamentos que ela expressa estão além da linguagem falada. (2004, p.103)

$\mathrm{O}$ ator tem, naturalmente, e sempre teve acesso à sua fisicalidade em diferentes gêneros históricos do teatro, mas é perceptível como a consciência e o desenvolvimento da expressão física no século $X X$ se torna um afastamento do realismo, quando a discussão do corpo liberado e expressivo forma seu próprio discurso. Porque quando o ator eleva o físico, é uma reivindicação do eu independente; um artista livre emerge, colocado em uma relação com o diretor e o dramaturgo. As pa- lavras de um drama são propriedade comum, qualquer pessoa pode dar voz a elas. Mas o próprio corpo é exatamente esse - próprio de cada um - e não pode ser apropriado ou citado da mesma maneira que um texto. Um texto pode ser preservado através do tempo como uma constante, mas o corpo está sujeito aos caprichos da biologia. Assim, o corpo tem um valor específico para o ator no palco, mas é ao mesmo tempo transitório, e condenado a murchar e morrer. O texto é imortal, diferente do corpo. E o dramaturgo pode colher a glória eterna, mas o ator é celebrado no agora e, na melhor das hipóteses, tornar-se-á uma lembrança ou uma anedota. Assim, a aspiração do ator de ser um artista independente faz do corpo uma ferramenta com uma posição específica: uma ferramenta para expressar a arte individual e as escolhas artísticas individuais.

Diante desse ponto de vista, o texto escrito do drama assume uma função que posiciona a criatividade do ator como dependente ou subordinada ao texto. No entanto, pode-se também observar uma série de reações contrárias a esta abordagem. Entre essas, é possível distinguir uma série de práticas diferentes, divergentes em atitude ideológica e artística: aqui temos ligações com a ênfase de Bertolt Brecht sobre a atitude social do corpo e da mente em Haltung 4 e Gestus; (Willett 1967, p.) aqui tam-

\footnotetext{
4 Nas Histórias de Brecht do Sr. Keuner (Brecht 2001) encontramos vários exemplos de seu conceito de Haltung, como "o que é sábio sobre o sábio é a sua postura": "Um professor de filosofia veio ver o Sr. K. e falou-lhe sobre Sua sabedoria. Depois de um tempo, o Sr. K. disse-Ihe: "Você senta desconfortavelmente, você fala desconfortavelmente, você pensa desconfortavelmente." O professor de filosofia ficou bravo e disse: "Eu não queria ouvir nada sobre mim, mas sobre a substância do que Eu estava falando." "Não tem substância", disse o Sr. K. "Eu vejo você andando desajeitadamente e, tanto quanto eu posso ver, você não está chegando a lugar nenhum. Você fala obscuramente, e você não cria luz com sua fala. Vendo a sua postura, não estou interessado no que você está conseguindo". (Brecht, 2001, p. 1)
} 
bém temos o desenvolvimento do método de ações físicas de Stanislavsky durante a década de 1930. (Toporkov, 1998, p.167, Pitches, 2006, p. 12) Exemplos mais radicais podem ser encontrados entre os já citados Artaud, Grotowski e o movimento de vanguarda americano do Living Theatre, mas também entre Eugênio Barba e a exploração antropológica da pré-expressividade do ator pelo Odin Teatret. Nas práticas contemporâneas, como o teatro comunitário e o colaborativo, a criação dos atores de seu próprio material por experiência pessoal é um exemplo de trabalho teatral sem um texto escrito como modelo. A criatividade corporal do ator e a capacidade de expressão física nos exemplos acima não negam o uso de um texto escrito, mas colocam o ator em outra posição em relação ao drama, uma posição que pode ser descrita como dominante ou igual.

Retiro rural e orientalismo: a busca por um corpo livre

Desejo agora retomar o argumento da fisicalidade do ator, como se expressou principalmente durante a última parte do século $X X$, e como ele continha um pensamento central de "liberdade física". Considerarei também o que impediu essa busca pela liberdade.

Podemos imaginar um corpo liberado? Podemos até mesmo considerar um corpo não afetado por regras, códigos ou a influência da sociedade? O que vemos então é talvez um Kaspar Hauser ou um Mogli, ou uma pessoa se comportando como um animal. Essa ideia de liberdade física não tem conotações agradáveis, talvez porque um corpo tão libertado seja demasiado intrusivo, muito autêntico e pertur- bador - ou seja, um pouco livre demais. Não é essa visão da liberdade física que discutirei aqui.

Outra imagem de um corpo liberado é descrita por palavras como "harmonioso", "equilibrado", "orgânico", "repleto de facilidade" ou "relaxado". Essa imagem positiva também contém uma ideia de uma relação mente-corpo ausente de conflito. Mas esse corpo, o ideal imaginado, está de alguma forma em desacordo com a sociedade moderna. A sociedade, num sentido amplo, é reivindicada por muitos como tendo prejudicado a relação do homem moderno com seu próprio corpo, através de inibições, regras de etiqueta, educação ou traumas psicológicos. Em um período em que nos são oferecidas curas físicas sem precedentes, há ao mesmo tempo uma suspeita de nosso bem-estar dentro de nossos corpos. O filósofo francês Jean Baudrillard (1998, p. 129) afirma que "o corpo se tornou hoje objeto de salvação. Ele assumiu literalmente a função moral e ideológica da alma". Ao dizer isto, expressa essa aspiração de recuperar o corpo culto, mas ao mesmo tempo o natural. Este corpo liberado, livre ou harmonioso não pertence a todos, hoje, mas ainda está ao alcance de quem deseja trabalhar por ele, ou talvez o comprar - hoje esse corpo é também uma mercadoria num mercado lucrativo.

Essa desconfiança em relação à reestruturação do corpo por parte da modernidade pode também, como discutido anteriormente, ser encontrada na retórica sobre o corpo do ator, na discussão do desenvolvimento do corpo e dos obstáculos para fazer do corpo uma ferramenta de trabalho artístico.

Podemos todos concordar facilmente sobre alguns aspectos do trabalho corporal de um ator: a capacidade de controlar o corpo 
e usá-lo para expressar pensamentos e concepções, uma sensibilidade a outros atores e aos estímulos internos e externos, uma conexão sensual consigo próprio e com o ambiente, etc. Termos mais comumente usados são "orgânico", "autêntico" ou "espontâneo". Um termo ainda mais geral pode abranger esses ideais: liberdade. O que se deseja é a liberdade de tensão, de bloqueios, de inibição:

A prática do movimento é um processo libertador. Liberdade aqui significa o trampolim, o ponto de prontidão para trazer a si mesmo e seu corpo a serviço da atuação... Você tem a força para deixar seu corpo livre e para integrar cada parte de você. (Pisk, 1975, p. 10)

Esses bloqueios podem vir de experiências privadas, psicológicas, mas também são comumente vistos como sujeitos à influência da sociedade, através da urbanização, divisão do trabalho ou mecanização. No Paradise Now de 1968, o Living Theatre exortou o público a:

- Teatro gratuito. Porque na sociedade que imaginamos, todo mundo é livre.

- Teatro gratuito. Ser livre. Vida livre. Faça qualquer coisa. Faça nada. Seja.

- Respire.

- Expanda a consciência. (Innes, 1993, p. 190)

Palavras como espontaneidade, impulso e sentimento são fundamentais para a compreensão, sobretudo, do teatro inovador das décadas de 1960 e 1970 e do tipo específico de crítica à civilização que se caracteriza pela visão do corpo como uma área de libertação. Isso é mais claramente formulado por Jerzy Grotowski, que queria que o impulso interno e a expressão externa fossem um e o mesmo, sendo o trabalho do ator voltado à intenção de eliminar a censura física. Ele também escreve:
"O ritmo da vida na civilização moderna é caracterizado pelo ritmo, tensão, um sentimento de desgraça, o desejo de esconder nossos motivos pessoais e o pressuposto de uma variedade de papéis e máscaras na vida". (Grotowski, 1975, p. 211) Nessa discussão, a separação cartesiana entre corpo e mente é vista como prejudicial à unidade do corpo atuante. Mas, por outro lado, a divisão é, mais ou menos conscientemente, assumida axiomaticamente como processos mentais são considerados intelectuais, enquanto a fisicalidade está mais ligada à intuição e aos sentimentos.

Para revitalizar o corpo e encontrar novas fontes para a criatividade, muitos praticantes do teatro ocidental do século XX voltaram seu olhar para o leste, para culturas consideradas mais primordiais. O dramaturgo indiano e crítico cultural Rustom Bharucha descreve este fascínio por outras culturas - especialmente o Oriente - como parte da política da interculturalismo:

$\mathrm{Na}$ verdade, pode-se argumentar que o interculturalismo nasceu de um certo aborrecimento, uma reação à aridez e à busca subsequente de novas fontes de energia, vitalidade e sensualidade através da importação de "matérias-primas rejuvenescedoras". Precisamos questionar as implicações dessa importação para as "outras" culturas (não-ocidentais). (1996, p. 207)

A educação física dos atores durante o século XX é caracterizada por uma tendência ao orientalismo ${ }^{5}$. Muitas técnicas de práticas e movimentos pedagógicos durante o século $X X$

5 Como descrito no Orientalismo de Edward Said (1978), este termo se refere à persistente tendência do mundo ocidental de definir o mundo não-ocidental como sendo o oposto polar do Ocidente - irracional, despótico, sensual e regressivo, em oposição ao ocidental racional, justo, disciplinado e progressista. 
são influenciados por técnicas e pensamentos tomados do Extremo Oriente. Isto se aplica não somente à educação, mas também a muitos dos diretores inovadores do século $X X$, que foram influenciados por artes teatrais de Extremo Oriente. Peter Brook, Ariane Mnouchkine, Bertolt Brecht, Antonin Artaud, Eugenio Barba e Jean-Louis Barrault usaram, em certa medida, ou durante certos períodos, elementos visuais ou técnicas físicas advindas do teatro asiático.

Inspirado por seu assistente Leopold Sulerzhitsky, Constantin Stanislavsky ficou fascinado pelo ioga e pelo hinduísmo, e seu uso de termos como 'supraconsciência' deve ser entendido nesse contexto, não em um freudiano. (Carnicke, 1998, p. 142, 211-2) Stanislavsky também desenvolveu exercícios onde era esperado que os atores irradiassem força vital universal, prana, através das palmas das mãos. (Carnicke, 1998, p. 141-2) Pode ser esse tipo de treinamento de atores que Bharucha descreve como "uma obsessão neocolonial com materiais e técnicas do "terceiro mundo". Bharucha (1996, p. 199 - 200) também criticou, com o mesmo espírito, a produção do Mahabharata do diretor inglês Peter Brook. Brook afirma que um conjunto que trabalha em conjunto sob circunstâncias fortuitas faz com que coisas como geografia e história deixem de existir. $O$ ideal é um encontro em terreno neutro, onde todos possam contribuir com a bagagem do seu próprio passado: "em vez de uma preocupação cultural, há uma preocupação dhármica, então fios de expressão diferentes e individuais podem encontrar o caminho para este momento zero". (Schechner Et al., 2002, p, 248) Do mesmo modo, Brook vê poucos problemas com o que a artista e curadora cubana Coco Fusco chama de multiculturalismo feliz. Ele parece desconhecer as implicações coloniais na seguinte citação notável: "Então, em 1973, eu e onze atores fomos para a África onde aprendemos a des-intelectualizar nosso trabalho". (Schechner Et al., 2002, p. 224)

Em uma entrevista de 1989, a diretora francesa Ariane Mnouchkine cita Antonin Artaud, incentivando seus atores a "olhar para o Oriente":

\begin{abstract}
Artaud disse: 'Teatro é Oriente.' ... Eu acredito que Artaud está certo. Então eu digo aos atores para ir procurar tudo no Oriente. Mito e realidade, interioridade e exteriorização, e a famosa autópsia do coração pelo corpo de que falamos. Também vamos procurar o não-realismo ou a teatralidade. (apud Féral, 2002, p. 264)
\end{abstract}

Este uso de culturas estrangeiras tem sido criticado como um exemplo de uma atitude pós-colonial, benevolente, mas desinformada, entre outros Coco Fusco. (2002, p. 226) Ela aponta para a tradição ocidental de exibir pessoas de cor como selvagens nobres em feiras e tribunais e afirma que isso foi "as origens do desempenho intercultural no Ocidente". Modernismo precoce, por exemplo o cubismo, separou-se do realismo imitando o que Fusco (2002, p. 269-271) chama de Primitivo. O bom vanguardista se tornou uma versão melhor do primitivo, uma drag queen cultural. Fusco fala de "multiculturalismo feliz" contemporâneo, alegando que esse fenômeno faz parte de festivais de arte multiculturais contemporâneos, cimentando a imagem do observador branco como consumidor da cultura global. Nisso há também uma ênfase implícita na autenticidade como valor estético:

A posição central do espectador branco, o objetivo desses eventos como uma confirmação de sua posição 
como consumidores globais de culturas exóticas, e a ênfase na autenticidade como um valor estético, todos permanecem fundamentais para $\mathrm{O}$ espetáculo de Alteridade que muitos continuam a desfrutar. (Fusco, 2002, p. 272)

Encontrei uma aproximação similar quando vi a oficina do diretor Eugênio Barba num seminário em Sevilha em 2004. Estando ao lado do dançarino, Barba demonstrou a máscara javanesa e a dança topeng de forma comentada, explicando, e esclarecendo o processo. $O$ bailarino era claramente um objeto nas mãos de Barba: ele ficou rígido e congelou seus movimentos sempre que Barba forneceu longas explicações. Através do intérprete, Barba deu mais instruções ao bailarino, que não entendia o inglês. Barba eleva e elogia o corpo do bailarino como portador de uma valiosa tradição, mas é Barba quem mantém o controle sobre a linguagem do especialista, discutindo as ações dos dançarinos e os posicionando em relação a outras técnicas teatrais. Minhas associações evocam a antropologia social dos velhos tempos.

Um tema recorrente entre os pioneiros do século XX no ensino teatral e no teatro inovador em geral é a 'fuga para o campo': "A des-urbanização é um processo reconhecível na história do treinamento de atores do século $X X$. Stanislavsky, Vakhtangov, Brook e Copeau, em alguns pontos, procuraram retiros rurais para 0 seu trabalho". (Hodge, 2000, p. 226) Em 1924, o diretor francês Jacques Copeau, que estava entre os principais renovadores do teatro francês em seu teatro parisiense do Vieux-Colombier, mudou sua escola para uma fazenda na Borgonha, a fim de redefinir os fundamentos de sua obra e escapar à influência do teatro de Boulevard, bem como os vanguardistas. (Ru- dlin, 2000, p. 61) Jerzy Grotowski passou seus últimos anos conduzindo seu trabalho de uma casa velha em uma colina arborizada na Toscana. (Richards, 1995, p. 33) O renovador de teatro aparentemente mais consistente neste movimento rousseauniano é o diretor polonês Włodzimierz Staniewski, que, depois de cooperar com Grotowski no início dos anos 1970, formou sua própria trupe no interior da Polônia. Junto com os aldeões, o grupo explorou mitos, danças, canções e tradições orais. A prática era dirigida contra a civilização ocidental racional, mas também era uma reação ao realismo social apoiado pelos comunistas no teatro polonês. (Hodge, 2000, p. 227-8) Argumento que isso, e buscas semelhantes por algo virginal na instrução do ator, traz consigo um pressuposto fundamental: a civilização moderna inibe e corrompe o ator. Há um corpo reprimido para liberar. Para atingir esse objetivo, teatro e corpo têm que redescobrir suas raízes originais, o que é mais facilmente feito em reclusão.

Este escapismo parece se basear numa presunção de que o corpo não está à vontade na civilização, talvez tão pouco na cultura. Uma linha de escapismo é que o corpo precisa ser reintroduzido em um estado mais primordial de harmonia, em contato com a Terra, ou no comportamento orgânico do animal, ou no nível espontâneo e intuitivo da criança. Outra linha de escapismo é a Idade de Ouro imaginária em estágios iniciais de desenvolvimento, com seu imaginado e paradisíaco Shangri-La, onde fisicalidade, sabedoria e conexão entre alma e corpo ainda não foram arruinadas pela sociedade ocidental. Minha conclusão é que partes significativas do modernismo teatral mostraram tendências claras ao escapismo e eram notavelmente hostis à modernidade.

Procurei mostrar ambos os aspectos das 
tradições dentro das instruções teatrais, pois elas contribuem para uma contextualização e inspeção crítica da educação dos atores e a retórica usada para legitimar vários exercícios. O propósito não é sugerir um tabu de técnicas de origem não-ocidental, ou do artista intérprete ou executante que fica no campo. No entanto, gostaria de chamar a atenção para os aspectos problemáticos das técnicas e tradições estrangeiras quando se transformam em exotismo, kitsch ou escapismo. O pesquisador de teatros Mark Evans (2014, p. 154-5) discute uma maneira de sair desse dilema quando afirma que "gosto do conceito de infecção cultural como uma metáfora para a transmissão de práticas corporais ... A questão é tanto cruzar fronteiras culturais quanto "penetrar" nossas próprias culturas nativas”.

Técnicas libertadoras liberdade ou mercantilização?

Há, como estamos bem familiarizados, técnicas para liberar o corpo, e a quantidade de técnicas oferecidas ao ator deve razoavelmente nos dizer algo sobre como é complicado libertar ou desenvolver o corpo.

Algumas técnicas corporais usadas regularmente no teatro sueco, mas certamente usadas na maior parte do mundo ocidental, são: aikidô, ioga, Tai Chi, a técnica Suzuki japonesa, flamenco, dança africana, tango, contato improvisação, mímica, euritmia de Dalcroze, acrobacia, boxe, massagem, relaxamento e técnica de Alexander. A essas, podemos adicionar várias técnicas mais ou menos locais desenvolvidas dentro dos programas educacionais em várias escolas de teatro. Mesmo que estas técnicas difiram enormemente em alcance e efei- tos esperados, o que a maioria delas têm em comum é a disciplina corporal implicada por elas, e às vezes a demanda por um especialista - ou um Mestre - para ensiná-las. Existem também algumas outras técnicas que são marcas registradas e exigem instrutores especificamente certificados, como Alba Emoting e o método Feldenkrais, um fato que aponta para o potencial de mercantilização neste campo. Podemos também encontrar, dentro de certas técnicas, uma luta sobre o desempenho correto. Muitas das técnicas mencionadas exigem trabalho árduo, capacidade de suportar dor e vontade de fazer sacrifícios.

O anti-convencionalismo e a liberação das autoridades e outras forças inibitórias parecem se conectar muito bem com outra ordem, um projeto de disciplina. Esta disciplina carrega a promessa da liberdade futura - e este pode muito bem ser o caso.

A pletora de técnicas também exibe diversidade, capacidade de escolha e um mercado em funcionamento. Aqui, mais uma vez quero traçar paralelos com Baudrillard e sua ideia do corpo como capital, algo para investir. A discussão de Baudrillard não se refere especificamente ao teatro, mas sim à sociedade ocidental em geral. Entretanto, parece razoável que a ideia de um capital corpóreo se aplique duplamente ao ator, cujo corpo é um tipo de objeto público para os olhares dos outros. O corpo se torna, de acordo com Baudrillard, (1998, p. 130) uma imagem tangível ou um empacotamento do próprio eu e, nesse sentido, um objeto a ser tratado como uma coisa a ser cuidada. Ao mesmo tempo, pode receber o papel de um sujeito completamente autônomo e místico, num dualismo pronunciado: deve-se ouvir o próprio corpo, ou descobri-lo através de um tipo particular de responsividade, ou amá-lo. 
Por extensão, vemos a capacidade de lidar com o próprio corpo como o maior indicador de liberdade, competência e disciplina. Isso também pode ser encontrado na vanguarda do século $X X$, mas também inesperadamente na indústria cinematográfica: na tradição do Método que ainda domina em Hollywood, e muitas vezes em outros lugares, é um negócio importante - literalmente - como os atores são transformados em seus personagens. Esta reconstrução do corpo, que toca principalmente os sujeitos mais carregados da sociedade de hoje - o peso - é muitas vezes retratado como uma saga heróica, com o herói passando por um purgatório de dieta e exercício para ganhar ou perder dezenas de quilos.

\section{Observações finais}

As tentativas, durante o século $X X$, de encontrar liberdade além do texto deram origem a uma fuga da época, mas também a subjugação sob novos regimes físicos, bem como uma atitude consumista em relação ao desenvolvimento do próprio eu. Em busca da liberdade, o ator, como outros cidadãos de uma sociedade consumista, também se tornou um bom consumidor. A liberdade foi alcançada através do consumo de técnicas libertadoras, e o que vemos na instrução física do teatro do século $X X$, especialmente nas últimas décadas, é a mesma coisa que no resto da sociedade: mais produtos e maior consumo. A liberdade se manifesta na possibilidade pessoal de fazer escoIhas. A multiplicidade de técnicas disponíveis leva à possibilidade de fazer escolhas individuais, mostrando a consciência de que o corpo é único e, portanto, necessita de uma combinação especial de técnicas para a liberdade.
Na minha opinião, isto vale não apenas para treinamento corporal e técnicas, mas para métodos de atuação em geral. Há ceticismo em relação a métodos vistos como manuais de trabalho, mas existe - paradoxalmente - um grande interesse em técnicas libertárias e escolhas pessoais destinadas a promover o próprio desenvolvimento físico e mental.

Hoje, vejo uma abordagem mais ideologicamente crítica para o treinamento corporal entre os estudantes de atuação. Os ideais predominantes, vestidos em termos como "natural", "orgânico" ou "autêntico", têm sido cada vez mais questionados como parte de um debate crítico sobre identidade nos últimos anos. Há, na discussão de hoje sobre identidade, individualidade e crítica de norma, uma busca pelo corpo individual. Essa autenticidade do indivíduo não se baseia num conceito de essência ou natureza, mas sim numa ideia de construtivismo social: sou quem sou, e os ideais corporais são normativos e podem, portanto, ser uma ameaça à minha individualidade. Em vez de procurar a natureza e a autenticidade, o jovem ator pode estar procurando por identidades diferentes, não só no palco, mas também em sua vida privada. A atitude em relação à identidade - às vezes também à gênero - é definida pela performatividade: executo minha identidade ou gênero, e devo estar ciente do que faço e expresso como uma criatura performativa. Esse espírito construtivista também acomoda a visão do próprio corpo como um documento, criado através da negociação entre diferentes escolhas de identidade.

Numa discussão contemporânea sobre técnicas corporais, vejo uma atitude mais cuidadosa em relação ao que geralmente é chamado de orientalismo. Um maior conhecimento da situação dentro das culturas não europeias, 
entre outras coisas a discussão pós-colonial, criou a dúvida de que há uma sabedoria oriental específica, ou que existem lugares na Terra onde os corpos são mais primordiais e autênticos. Um interesse crescente na ciência cognitiva cria uma discussão sobre a consciência e a conexão do corpo com o pensamento, uma discussão que tenta dissolver a oposição entre sentimento e intelecto.

Portanto, minha impressão subjetiva é que a educação corporal dos atores, hoje, está lentamente reivindicando um ponto de vista mais relativista. De acordo com Baudrillard, o corpo é visto como um projeto de auto-expressão e salvação que poderia, naturalmente, levar a fenômenos próximos à psicoterapia ou a um amplo campo de pseudo-terapias. Mas é claro que até aqui vemos uma multiplicidade de abordagens. Assim como as artes da performance são um campo de alargamento, assim também são os métodos de treinamento. As técnicas ligadas a diferentes tipos de ciências cognitivas podem ser vistas com mais freqüência. Uma das figuras retóricas mais fortes do discurso contemporâneo é se referir à pesquisa cognitiva - por exemplo, como as teorias sobre os neurônios-espelho podem ser conectadas ao trabalho dos atores. Isso está de acordo com o ponto de vista encontrado em Joseph Roach (1993, p.11): cada método de treinamento está se justificando de acordo com idéias contemporâneas mais ou menos científicas.

\section{- Referências}

ARTAUD, Antonin. Artaud on Theatre. Chicago: Ivan R. Dee, 2004.
BARRAULT, Jean-Louis. Dramatic Art and the Mime. In: B. Rolfe, ed. Mimes on Miming. Writings on the Art of Mime. London: Millington, 1979, p.109-10.

BAUDRILLARD, Jean. The Consumer Society. Myths and Structure. Trad. Chris Turner. London: SAGE, 1998.

BHARUCHA, Rustom. Somebody's Other. Disorientations in the Cultural Politics of Our Times. In: P. Pavis, ed. The Intercultural Performance Reader. London: Routledge, 1996, p.196-216.

BRECHT, Bertolt. Stories of Mr. Keuner. Trad. Martin Chalmers. San Francisco: City Lights Books, 2001.

CARNICKE, Sharon Marie. Stanislavsky in Focus. Amsterdam: Harwood Academic, 1998.

EVANS, Mark. Movement Training for the Modern Actor. New York: Routledge, 2009.

Playing with History: Personal Accounts of the Political and Cultural Self. In Actor Training Through Movement. Theatre, Dance and Performance Training, 5 (2), 2014, p. 144 $-156$.

FÉRAL, J. Building up the Muscle. An Interview with Ariane Mnouchkine. In: R. Schneider and G. Cody, eds. Re:direction: A Theoretical and Practical Guide. London: Routledge, 2002, p. 258-265. 
FUSCO, Coco. The Other History of Intercultural Performance. In: R. Schneider and G. Cody, eds. Re:direction: A Theoretical and Practical Guide. London: Routledge, 2002, p.266-280.

GROTOWSKI, Jerzy. Towards a Poor Theatre. London: Eyre Methuen, 1975.

HODGE, Alison. Włodzimierz Staniewski: Gardzienice and the Naturalised Actor. In: A. Hodge, ed. Twentieth Century Actor Training. London: Routledge, 2000, p. 224-244.

INNES, Christopher. Avant Garde Theatre 1892-1992. London: Routledge, 1993.

PISK, Litz. The Actor and his Body. London: Harrap, 1975.

PITCHES, Jonathan. Science and the Stanislavsky Tradition of Acting. London: Routledge, 2006.

RICHARDS, Thomas. At Work with Grotowski on Physical Actions. London: Routledge,1995.

ROACH, Joseph R. The Player's Passion. Studies in the Science of Acting. Ann Arbor: University of Michigan Press, 1993.

RUDLIN, Jean. Jacques Copeau. The Quest for Sincerity. In: A. Hodge, ed. Twentieth Century Actor Training. London: Routledge, 2000, p. 55-78.

SAID, Edward W. Orientalism. New York: Pantheon Books, 1978.
SCHECHNER, Richard. et al.. Talking with Peter Brook in: R. Schneider and G. Cody, eds. Re:direction: A Theoretical and Practical Guide. London: Routledge, 2002, p. $247-257$.

SEGEL, Harold B. Body Ascendant. Modernism and the Physical Imperative. London: Johns Hopkins University Press, 1998.

TOPORKOV, Vasili O. Stanislavski in Rehearsal. The Final Years. Trad. Christine Edwards. New York: Routledge/Theatre Arts Books, 1998.

WEDEKIND, Frank. Mine-Haha or On the Bodily Education of Young Girls. Trad. Philip Ward. London: Modern Voices, 2010.

WILLETT, John. The Theatre of Bertolt Brecht. A Study from Eight Aspects. 3rd rev. ed. London: Methuen, 1967.

Recebido em 15/12/2016 Aprovado em 23/12/2016 